\title{
Association between state physical education (PE) requirements and PE participation, physical activity, and body mass index change
}

Daniel R. Taber ${ }^{\text {a }}$, PhD, MPH; Jamie F. Chriqui ${ }^{\text {a,b }}$, PhD, MHS; Frank M. Perna ${ }^{\text {c }}$, EDD, PhD; Lisa M. Powell ${ }^{\mathrm{a}, \mathrm{d}}, \mathrm{PhD}$; Sandy J. Slater ${ }^{\mathrm{a}, \mathrm{d}}, \mathrm{PhD}$; Frank J. Chaloupka ${ }^{\mathrm{a}, \mathrm{e}}, \mathrm{PhD}$

${ }^{a}$ Institute for Health Research and Policy, University of Illinois at Chicago, 1747 W. Roosevelt Rd, Chicago, IL, 60608, United States

${ }^{\mathrm{b}}$ Department of Political Science, University of Illinois at Chicago, 1007 W. Harrison Street, Chicago, IL, 60607, United States

${ }^{\mathrm{c}}$ Division of Cancer Control and Population Sciences, National Cancer Institute, 6130 Executive Blvd., EPN Room 4070, Bethesda, MD, 20852, United States

${ }^{\mathrm{d}}$ Department of Health Policy and Administration, University of Illinois at Chicago, $1603 \mathrm{~W}$. Taylor Street, Chicago, IL, 60612, United States

${ }^{\mathrm{e}}$ Department of Economics, University of Illinois at Chicago, 601 South Morgan, Chicago, IL, 60607, United States

\section{Email addresses}

Daniel R. Taber: Daniel.Taber@uth.tmc.edu Lisa M. Powell: powelll@uic.edu Jamie F. Chriqui: jchriqui @uic.edu Sandy J. Slater: sslater@uic.edu

Frank M. Perna: pernafm@mail.nih.gov Frank J. Chaloupka: fjc@uic.edu

\section{Corresponding author}

Daniel R. Taber

University of Texas School of Public Health, Austin Regional Campus

1616 Guadalupe, Suite 6.300

Austin, TX 78701

Phone: 512-391-2519

\section{Word counts:}

Abstract: 199 Text: 2950 


\begin{abstract}
Objective: To determine if state physical education (PE) laws are associated with student PE attendance and physical activity (PA), and whether PE and competitive food laws, in conjunction, are associated with lower BMI change.
\end{abstract}

Method: State laws regarding PE time requirements and competitive foods in 2003 and 2006 were classified as strong, weak, or none, based on codified law ratings obtained from the Classification of Laws Associated with School Students. Laws were linked to student data on PE attendance and PA ( $8^{\text {th }}$ grade, Spring 2007$)$ and BMI change $\left(5^{\text {th }}-8^{\text {th }}\right.$ grade, 2004-2007), obtained from the Early Childhood Longitudinal Study ( $\mathrm{n}=5510$ students in 40 states).

Results: Girls reported 0.31 more days of activity (95\% CI: $0.02,0.61$ ) and were more likely to attend $\mathrm{PE} \geq 3$ days/week (74.1\% vs. 52.1\%, difference=22.0, 95\% CI: 2.1, 42.0) if they resided in states with strong PE laws compared to no PE laws. Weak PE laws had modest associations with $\mathrm{PE}$ and activity, and there was no evidence that weak laws reduce BMI gain regardless of competitive food laws.

Conclusion: Strong PE laws with specific time requirements may increase PE attendance and activity in girls. There is insufficient evidence that PE laws reduce student weight gain. 


\section{INTRODUCTION}

Childhood obesity is regarded as one of the primary public health concerns in the United States (U.S.) (Institute of Medicine, 2005) and is projected to become a greater burden over time (Bibbins-Domingo et al., 2007; Olshansky et al., 2005; Wang et al., 2011; World Health Organization, 2000). Though overall prevalence has been stable since 1999, it remains at an elevated level particularly among adolescents (18.4\% among 12-19 year-olds in 2009-10) (Ogden et al., 2012), which may contribute to future increases in adult obesity (Robinson et al., 2013) and coronary heart disease (Bibbins-Domingo et al., 2007).

Obesity is caused by a complex web of factors that influence diet, physical activity, and sedentary behaviors (Institute of Medicine, 2012; Johnson-Taylor and Everhart, 2006), leading experts to call for an array of policy initiatives (Huang et al., 2009; Huang and Glass, 2008; Institute of Medicine, 2010, 2012). One widely-promoted initiative is requiring children to participate in a minimum amount of physical education (PE) per week (Boehmer et al., 2007; Centers for Disease Control and Prevention, 2011; Eyler et al., 2010). It is recommended that schools provide 225 minutes of PE per week for middle and high school students (Centers for Disease Control and Prevention, 2011; National Association for Sport and Physical Education, 2004), but most schools fall short of these standards. In 2004-07, $8^{\text {th }}$-grade students participated in PE for an average of only 180 minutes/week, and participation dropped precipitously at higher grade levels ( $12^{\text {th }}$ grade mean $=82$ minutes/week) (O'Malley et al., 2009).

Some states have laws that require a minimum amount of PE, but most state laws fall short of NASPE and CDC recommendations (Lee et al., 2007; McCullick et al., 2012; Walker et al., 2010). The evidence base to support existing PE requirements as an obesity reduction measure is mixed. Studies of PE laws by Cawley et al. and Kim generally reported modest associations with physical activity (PA) and no association with weight status (Cawley et al., 2007; Kim, 2012), though a more recent study by Cawley et al. reported that PE time was inversely associated with BMI z-score and obesity among $5^{\text {th }}$-grade boys (Cawley et al., 2013).

Interestingly, Kim reported some evidence that school PE requirements were inversely associated with obesity in 2007 but not 2003 (Kim, 2012). As she noted, childhood obesity was a lower priority among policymakers in 2003 , but starting in 2006-07, school districts that participated in federal school meal programs were required to implement a wellness policy to improve school nutrition and promote PA (Child Nutrition and WIC Reauthorization Act of 
2004.) Kim speculated that PE policies might not have affected obesity until implemented in conjunction with nutrition policies, but this hypothesis is untested.

This study analyzed the association between PE laws and competitive food laws, in conjunction, and student weight gain over time, as well as the association between PE laws and $\mathrm{PE}$ attendance/PA. The study builds upon existing research by linking objective analysis of codified laws with repeated objective height and weight measurements in a cohort of 5510 schoolchildren in 40 states.

\section{METHODS}

\section{Student sample}

Student data were obtained from the Early Childhood Longitudinal Study-Kindergarten Class (ECLS-K) (Tourangeau et al., 2005; Tourangeau et al., 2009). ECLS-K began in 1998 when investigators sampled a nationally representative cohort of kindergarten students, whom they followed through seven rounds of data collection. For the purpose of this study, analyses of PE attendance and PA utilized data collected in Round 7 ( $8^{\text {th }}$ grade, Spring 2007), when these measures were obtained from students. (PE attendance and PA were collected from teachers and parents, respectively, in $5^{\text {th }}$ grade and thus are incomparable to $8^{\text {th }}$ grade data.) Analyses of BMI change utilized data from Round 6 ( $5^{\text {th }}$ grade, Spring 2004) and Round 7. Among the 9330 public school students who participated in $5^{\text {th }}$ grade data collection, 3820 were excluded from analyses because they enrolled in a private school $(n=130)$, moved states $(n=270)$, were lost to follow-up $(n=1790)$, or were missing data on $8^{\text {th }}$-grade school type $(n=240)$, PE attendance or PA $(n=320)$, or covariates $(n=1070)$, leaving a sample of 5510 students. Those lost to follow-up or excluded due to missing data were less likely to be non-Hispanic White $(\mathrm{p}<0.001)$ or play a sport in $5^{\text {th }}$ grade $(\mathrm{p}<0.001)$ and more likely to be male $(\mathrm{p}<0.001)$, live in an urban area $(\mathrm{p}<0.001)$, be in the lowest SES quintile ( $\mathrm{p}<0.001)$, or reside in a state with strong PE laws $(\mathrm{p}<0.001)$. They did not differ from the study sample in terms of $5^{\text {th }}$ grade weight status. Forty states were represented in the study sample; individual states cannot be listed due to data license restrictions. 


\section{Measures}

All student data collection was conducted by trained research staff during the school day. Using a written questionnaire, students reported the number of days they attended PE class in an average week and the number of days they engaged in at least 20 minutes of activity that made them sweat or breathe hard in the past week. Students also reported other measures of diet (e.g., sugar-sweetened beverage (SSB) consumption), PA (e.g., sports participation), and sedentary behaviors (e.g., television viewing). Student BMI (kilograms/meters ${ }^{2}$ ) was calculated from weight and height measurements obtained by ECLS-K staff using a digital scale and Shorr board, respectively.

\section{State law data}

Ratings of codified laws regarding state PE time requirements were obtained from the National Cancer Institute's Classification of Laws Associated with School Students (C.L.A.S.S.) Analyses in this study are based on middle school time requirement laws effective as of December 31, 2006. It should be pointed out that all but 3 states had the same rating in every year from 2003 to 2006 .

The C.L.A.S.S. PE law ratings system has been described extensively elsewhere (Masse et al., 2007); in brief, states were rated on a 0-5 scale according to their laws' stringency and specificity. For the purpose of this study, laws were re-coded as none, weak, or strong. States that were rated as $0-1$ were classified as having no time requirement law because these laws, at most, recommended but did not require PE. States with a rating of 2 were classified as having "weak" laws because they did not specify a minimum amount of PE. States were classified as having "strong" laws if they required a specific amount of PE (rating 3-5). These categories were used in previous research of C.L.A.S.S. time requirement laws (Perna et al., 2012).

Our analyses also utilized C.L.A.S.S. data on laws regarding competitive foods - i.e., foods sold outside of federal school meal programs. Competitive food laws were rated on a 0-6 scale based on regulations of specific nutrients, specific food/beverage groups, and times of day when foods/beverages could be sold. Using the same criteria applied in a previous study of C.L.A.S.S. competitive food laws (Taber et al., 2012), we classified states as having strong, weak, or no competitive food laws based on their average rating for laws in different school venues ( $>2=$ ="strong"; 1-2="weak"; 0="none"). 


\section{Statistical analysis}

Within-state correlation of PE attendance was very high in the study sample. State-level intraclass correlation coefficients (ICC) for PE attendance were 0.19 among girls, 0.15 among boys, and even higher in states with strong PE laws (see Appendix). Analyses of PE attendance and PA utilized mixed models with a state-level random intercept to control for within-state correlation.

All analyses were stratified by gender because previous studies reported that the effects of PE policies differed between boys and girls (Cawley et al., 2013; Cawley et al., 2007; Kim, 2012). First, we estimated differences in student PE attendance and PA between states with varying 2006 PE laws. PE attendance was modeled using two separate but overlapping binary outcomes - "regular" attendance (3 or more days/week) and daily attendance (5 days/week) - in logistic models using the 'xtmelogit' command in Stata, Version 11. The number of days of PA was modeled with a Poisson model ('xtpoisson'). Each mixed model controlled for race/ethnicity, locale, Census region, $5^{\text {th }}$-grade socioeconomic status (SES, measured using an index that combined data on parental education, parental occupation, and household income), sports participation, and hours of television watched on a typical weekday. For each of these models, the 'margin' command was used to calculate the average marginal effect of state laws.

We used an individual-level fixed-effect model to estimate the association between combinations of PE and competitive food laws and within-student BMI change between $5^{\text {th }}$ and $8^{\text {th }}$ grade. Students in states with weak PE laws were stratified based on their state's 2006 competitive food laws - strong $(n=1190)$, weak $(n=980)$, none $(n=1190)-$ and compared to students in states with no PE laws or competitive food laws ( $\mathrm{n}=290)$. Models adjusted for SES, locale, and consumption of SSBs and fast food. We intended to similarly stratify states with strong PE laws, but each state in this category had different patterns of competitive food laws from 2003 to 2006, and consequently the effect of strong PE and competitive food laws, in conjunction, could be biased by other state characteristics. Therefore, this analysis was limited to states with weak (i.e., nonspecific PE time requirements) or no PE time requirement laws. 


\section{RESULTS}

There were several demographic differences between states with different PE laws (Table 1). Students in states with strong laws were more likely to be Hispanic (40.7\%), reside in urban areas $(47.1 \%)$, or be in the lowest SES quintile (25.2\%), whereas students in states with weak laws were more likely to be non-Hispanic White (75.2\%) or in the highest SES quintile (22.8\%).

Adjusted analyses indicated that girls, in particular, were more likely to report regular PE attendance if they resided in states with strong PE laws (Table 2). In these states, $74.1 \%$ of girls reported regular attendance, versus $52.1 \%$ in states with no laws (average difference $=22.0,95 \%$ confidence interval (CI): 2.1,42.0). Regular attendance among girls was also more common in states with weak laws, but the difference was much smaller $(11.1,95 \%$ CI: -6.4, 28.6). Associations between state laws and regular attendance were also smaller among boys. When modeling daily PE attendance, difference estimates were smaller and very imprecise due to statelevel clustering. For example, the adjusted proportion of girls who reported daily PE was 8.3 percentage points higher in states with strong laws, and the standard error of this estimate was 12.9.

Strong PE laws were also positively associated with days of PA among girls (Table 3). On average, girls reported 0.31 more days of activity per week if they resided in states with strong laws, relative to states with no laws $(95 \% \mathrm{CI}: 0.02,0.61)$. Boys were estimated to have 0.20 more days of activity per week if they resided in states with strong laws (95\% CI: -0.14 , 0.54). As with PE attendance, differences in PA associated with weak PE laws were smaller among girls (difference $=0.23,95 \%$ CI: $-0.04,0.51)$ and boys $($ difference $=0.10,95 \%$ CI: -0.22 , $0.41)$.

Table 4 displays the association between within-student BMI change and combinations of $\mathrm{PE}$ and competitive food laws. Among girls, average BMI change (i.e., increase) was only 0.14 units lower in states with weak PE laws and no competitive food laws, relative to states with no PE or competitive food laws (95\% CI: -0.62, 0.34). There was modest evidence of lower BMI increase among girls in states with weak PE laws in combination with competitive food laws that were weak ( $\beta=-0.43,95 \% \mathrm{CI}:-0.93,0.07)$ or strong $(\beta=-0.35,95 \% \mathrm{CI}$ : $-0.84,0.13)$ compared to girls in states with no PE laws and no competitive food laws, but estimates were relatively imprecise due to the small sample size. There was no evidence of lower BMI increase among boys in any category. 


\section{DISCUSSION}

School administrators have expressed both enthusiasm and skepticism toward efforts to prevent childhood obesity via school-based nutrition and PE laws (Agron et al., 2010; Amis et al., 2012). States have shown more willingness to enact stronger competitive food laws, which developed relatively rapidly from 2003 to 2006, at a time when PE time requirement laws changed little and more than $75 \%$ of the states in this study did not have strong PE laws. Our results indicated that strong laws containing specific PE time requirements were positively associated with PE attendance and PA particularly among girls. The associations between weak PE laws and attendance or PA were in the hypothesized direction, but consistently smaller.

A recent study by Perna et al. similarly reported that middle schools in states with specific requirements reported 60 more minutes of PE per week, relative to states with nonspecific requirements. The authors concluded that having a nonspecific requirement was equivalent to having no law at all (Perna et al., 2012). Our study linked C.L.A.S.S. with studentlevel data from an independent data source, ECLS-K, and came to similar conclusions. Reported $\mathrm{PE}$ attendance among girls was considerably higher in states with specific requirements, to the point that the adjusted proportion of girls who reported regular PE attendance (74.1\%) was slightly higher than that of boys (70.8\%) in these states compared to $52.1 \%$ for girls and $57.6 \%$ for boys in states with no laws.

Cawley et al. and Kim similarly reported that state PE policies were associated with PA primarily among girls (Cawley et al., 2007; Kim, 2012). A more recent study by Cawley et al. reported the opposite, however, as girls appeared to substitute PE for individual sports and playground activities, and PE time was not associated with weight status among girls. This discrepancy across studies may be partially explained by age differences. Studies that reported a positive association among girls focused largely on adolescence, a time when girls become increasingly less active (Dumith et al., 2011; Kimm et al., 2002), whereas Cawley et al.'s 2013 study followed students through $5^{\text {th }}$ grade. Regardless, the common thread across studies is that any effect of PE laws on activity among girls did not translate into a significant effect on weight status. This lack of effect could be attributable to girls not getting sufficient volume or intensity of activity during PE class (McKenzie et al., 2006; Nader, 2003) or substituting PE time for other activities (Cawley et al., 2013). The effect of PE laws on PA and weight status could be 
improved with policies and programs that are designed to improve activity levels within class and promote an active lifestyle overall, as a complement to attendance laws.

Our analyses of the comprehensive effect of PE and competitive food laws cast further doubt on the adequacy of nonspecific PE time requirements. Weak PE laws were not associated with lower BMI change in either boys or girls. Even where there was modest e vidence of lower BMI change, such as states with weak PE laws and strong competitive food laws, the adjusted difference in BMI change was similar to the adjusted difference in BMI change associated with strong competitive food laws alone, as reported elsewhere (Taber et al., 2012). In other words, there is no evidence that nonspecific PE laws have any additive benefit.

This lack of effect on BMI change is largely a reflection of how weak and invariant PE laws have been over time. The causal link between PA and adiposity reduction has been questioned, particularly in the absence of changes in energy intake (Rennie et al., 2006; Wilks et al., 2011) so it is not surprising that any modest effect that weak PE laws have on PA would produce little difference in weight gain. At the time of this study, there were not a sufficient number of states with strong PE laws to determine if stronger PE laws and competitive food laws, in conjunction, can reduce BMI change. As states enact stronger PE laws, future longitudinal studies will be able to assess whether stronger laws are more effective at maintaining healthy weight or improving weight status.

Future studies should examine a broader range of health indicators that are associated with physical activity among school-aged youth, including cardiovascular, metabolic, musculoskeletal, and psychosocial outcomes (Janssen and Leblanc, 2010; Strong et al., 2005). This would provide a comprehensive assessment of the impact of PE laws on students' overall fitness, as opposed to simply their weight status. The effect of PE laws on academic outcomes (e.g., standardized test scores) should also be examined further. The challenges of requiring PE are particularly daunting to schools at a time when they face more pressure to meet academic standards (Amis et al., 2012). Resistance to PE requirements may subside if PE laws are found to improve academic performance. A review by Trudeau and Shephard concluded that physical activity during the school day can have a positive impact on student cognition while having no adverse effects on academic performance (Trudeau and Shephard, 2008). Cawley et al. likewise reported that PE time did not reduce time in academic courses or affect standardized test scores (Cawley et al., 2013). No study, to our knowledge, has examined the direct impact of PE laws 
on academic performance at higher grade levels, when PE class time is commonly reduced (O'Malley et al., 2009).

Our analyses of PA were limited by the PA measure, which was somewhat crude and did not measure activity within PE class. Additionally, both PE attendance and PA were measured via self-report instruments that could be biased (Sirard and Pate, 2001) and were collected from students only in $8^{\text {th }}$ grade. Future studies should attempt to obtain repeated, objective measures of activity, overall and within PE class. It should also be pointed out that the volume of missing data is a key limitation in this study and results should be interpreted cautiously.

Other studies may also incorporate measures of PE policies set at the district or school level and consider how specific measures of PE quality (e.g., facilities) modify state law effects. Law effects could also vary between states due to exemptions for medical, religious, or other reasons, which are known to vary by state (Lee et al., 2007). Such characteristics could explain the high degree of state clustering that we observed. ICC estimates for PE attendance were exceptionally high and suggest that some state laws were more effective than others. Overall, the proportion of girls who reported regular PE attendance was 22 percentage points higher in states with strong laws, but the magnitude of laws' effect on PE attendance is likely to vary considerably across states. Studies in Texas, a state with relatively stringent PE requirements, reported that these requirements improved students' PE attendance and physical activity (Barroso et al., 2009; Kelder et al., 2009). Future studies should identify state or policy characteristics that distinguish states such as Texas from those with similar laws that have experienced less success.

\section{Conclusion}

At this time, with PE laws being generally weak and invariant over time, there is not enough evidence to conclude that PE laws can reduce student weight gain, but the evidence does suggest that strong laws with specific time requirements are associated with higher PE attendance and PA levels among girls. Most states have opted for weaker laws with nonspecific requirements. Such laws do not suffice and this underscores the need for stronger PE laws. If states begin to target PE aggressively, as they have for competitive foods, then there will be future opportunities to determine if the comprehensive effect of strong PE and competitive food laws can reduce childhood obesity. 


\section{Conflict of Interest statement}

The authors declare that there are no conflicts of interest. 


\begin{abstract}
ABBREVIATIONS
C.L.A.S.S.: Classification of Laws Associated with School Students

E.C.L.S.K.: Early Childhood Longitudinal Study-Kindergarten Class
\end{abstract}

\title{
ACKNOWLEDGEMENTS
}

Support for this study was provided by the Robert Wood Johnson Foundation to the Bridging the Gap Program at the University of Illinois at Chicago (PI: Frank Chaloupka) and contracts HHSN261201000350P and HHSN261201100522P from the National Cancer Institute to the University of Illinois at Chicago (PI: Jamie Chriqui). The views expressed herein are solely those of the authors and do not reflect the official views or positions of the Robert Wood Johnson Foundation; the National Heart, Lung, and Blood Institute; the National Cancer Institute; or the National Institutes of Health.

The authors would also like to gratefully acknowledge Tamkeen Khan for her research assistance with cleaning the individual-level ECLS-K data. 


\section{REFERENCES}

Agron, P., Berends, V., Ellis, K., Gonzalez, M., 2010. School wellness policies: perceptions, barriers, and needs among school leaders and wellness advocates. J. Sch. Health 80:527-35.

Amis, J.M., Wright, P.M., Dyson, B., Vardaman, J.M., Ferry, H., 2012. Implementing childhood obesity policy in a new educational environment: the cases of Mississippi and Tennessee. Am. J. Public Health 102:1406-13.

Barroso, C.S., Kelder, S.H., Springer, A.E., Smith, C.L., Ranjit, N., Ledingham, C., Hoelscher, D.M., 2009. Senate Bill 42: implementation and impact on physical activity in middle schools. J. Adolesc. Health 45:S82-90.

Bibbins-Domingo, K., Coxson, P., Pletcher, M.J., Lightwood, J., Goldman, L., 2007. Adolescent overweight and future adult coronary heart disease. N. Engl. J. Med. 357:2371-9.

Boehmer, T.K., Brownson, R.C., Haire-Joshu, D., Dreisinger, M.L., 2007. Patterns of childhood obesity prevention legislation in the United States. Prev Chronic Dis 4:A56.

Cawley, J., Frisvold, D., Meyerhoefer, C., 2013. The impact of physical education on obesity among elementary school children. J. Health Econ. 32:743-55.

Cawley, J., Meyerhoefer, C., Newhouse, D., 2007. The impact of state physical education requirements on youth physical activity and overweight. Health Econ. 16:1287-301.

Centers for Disease Control and Prevention, 2011. School health guidelines to promote healthy eating and physical activity. MMWR Recomm Rep 60:1-76.

Dumith, S.C., Gigante, D.P., Domingues, M.R., Kohl, H.W., 3rd, 2011. Physical activity change during adolescence: a systematic review and a pooled analysis. Int. J. Epidemiol. 40:685-98. 
Eyler, A.A., Brownson, R.C., Aytur, S.A., Cradock, A.L., Doescher, M., Evenson, K.R., Kerr, J., Maddock, J., Pluto, D.L., et al., 2010. Examination of trends and evidence-based elements in state physical education legislation: a content analysis. The Journal of school health 80:326-32.

Huang, T.T., Drewnowski, A., Kumanyika, S.K., Glass, T.A., 2009. A systems-oriented multilevel framework for addressing obesity in the 21st century. Prev Chronic Dis 6:A97.

Huang, T.T., Glass, T.A., 2008. Transforming research strategies for understanding and preventing obesity. JAMA : the journal of the American Medical Association 300:1811-3.

Institute of Medicine, 2005. Preventing Childhood Obesity: Health in the Balance. National Academies Press, Washington, D.C.

Institute of Medicine, 2010. Bridging the Evidence Gap in Obesity Prevention: A Framework to Inform Decision Making. The National Academies Press, Washington, DC.

Institute of Medicine, 2012. Accelerating Progress in Obesity Prevention: Solving the Weight of the Nation. The National Academies Press, Washington, DC.

Janssen, I., Leblanc, A.G., 2010. Systematic review of the health benefits of physical activity and fitness in school-aged children and youth. Int J Behav Nutr Phys Act 7:40.

Johnson-Taylor, W.L., Everhart, J.E., 2006. Modifiable environmental and behavioral determinants of overweight among children and adolescents: report of a workshop. Obesity (Silver Spring) 14:929-66.

Kelder, S.H., Springer, A.S., Barroso, C.S., Smith, C.L., Sanchez, E., Ranjit, N., Hoelscher, D.M., 2009. Implementation of Texas Senate Bill 19 to increase physical activity in elementary schools. J. Public Health Policy 30 Suppl 1:S221-47.

Kim, J., 2012. Are physical education-related state policies and schools' physical education requirement related to children's physical activity and obesity? J. Sch. Health 82:268-76. 
Kimm, S.Y., Glynn, N.W., Kriska, A.M., Barton, B.A., Kronsberg, S.S., Daniels, S.R., Crawford, P.B., Sabry, Z.I., Liu, K., 2002. Decline in physical activity in black girls and white girls during adolescence. N. Engl. J. Med. 347:709-15.

Lee, S.M., Burgeson, C.R., Fulton, J.E., Spain, C.G., 2007. Physical education and physical activity: results from the School Health Policies and Programs Study 2006. J. Sch. Health 77:435-63.

Masse, L.C., Chriqui, J.F., Igoe, J.F., Atienza, A.A., Kruger, J., Kohl, H.W., 3rd, Frosh, M.M., Yaroch, A.L., 2007. Development of a Physical Education-Related State Policy Classification System (PERSPCS). Am. J. Prev. Med. 33:S264-76.

McCullick, B.A., Baker, T., Tomporowski, P.D., Templin, T.J., Lux, K., Isaac, T., 2012. An analysis of state physical education policies. J Teach Phys Educ 31:200-10.

McKenzie, T.L., Catellier, D.J., Conway, T., Lytle, L.A., Grieser, M., Webber, L.A., Pratt, C.A., Elder, J.P., 2006. Girls' activity levels and lesson contexts in middle school PE: TAAG baseline. Med. Sci. Sports Exerc. 38:1229-35.

Nader, P.R., 2003. Frequency and intensity of activity of third-grade children in physical education. Arch. Pediatr. Adolesc. Med. 157:185-90.

National Association for Sport and Physical Education, 2004. Moving Into the Future: National Standards for Physical Education, 2nd ed. NASPE, Reston, VA.

O'Malley, P.M., Johnston, L.D., Delva, J., Terry-McElrath, Y.M., 2009. School physical activity environment related to student obesity and activity: a national study of schools and students. J. Adolesc. Health 45:S71-81.

Ogden, C.L., Carroll, M.D., Kit, B.K., Flegal, K.M., 2012. Prevalence of obesity and trends in body mass index among US children and adolescents, 1999-2010. JAMA 307:483-90. 
Olshansky, S.J., Passaro, D.J., Hershow, R.C., Layden, J., Carnes, B.A., Brody, J., Hayflick, L., Butler, R.N., Allison, D.B., et al., 2005. A potential decline in life expectancy in the United States in the 21 st century. N. Engl. J. Med. 352:1138-45.

Perna, F.M., Oh, A., Chriqui, J.F., Masse, L.C., Atienza, A.A., Nebeling, L., Agurs-Collins, T., Moser, R.P., Dodd, K.W., 2012. The association of state law to physical education time allocation in US public schools. Am. J. Public Health 102:1594-9.

Rennie, K.L., Wells, J.C., McCaffrey, T.A., Livingstone, M.B., 2006. The effect of physical activity on body fatness in children and adolescents. Proc. Nutr. Soc. 65:393-402.

Robinson, W.R., Keyes, K.M., Utz, R.L., Martin, C.L., Yang, Y., 2013. Birth cohort effects among US-born adults born in the 1980s: foreshadowing future trends in US obesity prevalence. Int. J. Obes. 37:448-54.

Sirard, J.R., Pate, R.R., 2001. Physical activity assessment in children and adolescents. Sports Med. 31:439-54.

Strong, W.B., Malina, R.M., Blimkie, C.J., Daniels, S.R., Dishman, R.K., Gutin, B., Hergenroeder, A.C., Must, A., Nixon, P.A., et al., 2005. Evidence based physical activity for school-age youth. J. Pediatr. 146:732-7.

Taber, D.R., Chriqui, J.F., Perna, F.M., Powell, L.M., Chaloupka, F.J., 2012. Weight status among adolescents in States that govern competitive food nutrition content. Pediatrics 130:43744.

Tourangeau, K., Le, T., Nord, C., 2005. Early Childhood Longitudinal Study, Kindergarten Class of 1998-99 (ECLS-K): fifth-grade methodology report (NCES 2006-037), in: Education, U.S.D.o. (Ed.). National Center for Education Statistics, Washington D.C.

Tourangeau, K., Le, T., Nord, C., Sorongon, A.G., 2009. Early Childhood Longitudinal Study, Kindergarten Class of 1998-99 (ECLS-K): eighth-grade methodology report (NCES 2009-003), 
in: Education, U.S.D.o. (Ed.). National Center for Education Statistics, Institute of Education Sciences, Washington D.C.

Trudeau, F., Shephard, R.J., 2008. Physical education, school physical activity, school sports and academic performance. Int J Behav Nutr Phys Act 5:10.

Walker, E., Chriqui, J.F., Chiang, R.J., 2010. Obesity Prevention Policies for Middle and High Schools: Are We Doing Enough? National Association of State Boards of Education, Arlington, VA.

Wang, Y.C., McPherson, K., Marsh, T., Gortmaker, S.L., Brown, M., 2011. Health and economic burden of the projected obesity trends in the USA and the UK. Lancet 378:815-25.

Wilks, D.C., Besson, H., Lindroos, A.K., Ekelund, U., 2011. Objectively measured physical activity and obesity prevention in children, adolescents and adults: a systematic review of prospective studies. Obesity reviews : an official journal of the International Association for the Study of Obesity 12:e119-29.

World Health Organization, 2000. Obesity : preventing and managing the global epidemic. World Health Organization, Geneva. 